\title{
Post-Training Cyclooxygenase-2 (COX-2) Inhibition Impairs Memory Consolidation
}

\author{
Lisa A. Teather, ${ }^{1,4,5}$ Mark G. Packard ${ }^{3}$ and Nicolas G. Bazan ${ }^{1,2}$ \\ ${ }^{1}$ Neuroscience Center of Excellence and ${ }^{2}$ Department of Ophthalmology, Louisiana State University Health Center, New Orleans, Louisiana \\ 70112, USA; and ${ }^{3}$ Department of Psychology, Yale University, New Haven, Connecticut 06520, USA
}

\begin{abstract}
Evidence indicates that prostanoids, such as prostaglandins, play a regulatory role in several forms of neural plasticity, including long-term potentiation, a cellular model for certain forms of learning and memory. In these experiments, the significance of the COX isoforms cyclooxygenase-1 (COX-1) and cyclooxygenase-2 (COX-2) in post-training memory processes was assessed. Adult male Long-Evans rats underwent an eight-trial (30-sec intertrial interval) training session on a hippocampus-dependent (hidden platform) or dorsal striataldependent (visible platform) tasks in a water maze. After the completion of training, rats received an intraperitoneal injection of the nonselective COX inhibitor indomethacin, the COX-1-specific inhibitor piroxicam, the COX-2-specific inhibitor $N$-[2-cyclohexyloxy-4-nitrophenyl]-methanesulfonamide (NS-398), vehicle (45\% 2-hydroxypropyl- $\beta$-cyclodextrin in distilled water), or saline. On a two-trial retention test session $24 \mathrm{~h}$ later, latency to mount the escape platform was used as a measure of memory. In the hidden platform task, the retention test escape latencies of rats administered indomethacin $(5$ and $10 \mathrm{mg} / \mathrm{kg}$ ) or NS-398 (2 and $5 \mathrm{mg} / \mathrm{kg}$ ) were significantly higher than those of vehicle-treated rats, indicating an impairment in retention. Injections of indomethacin or NS-398 that were delayed $2 \mathrm{~h}$ post-training had no effect on retention. Post-training indomethacin or NS-398 had no influence on retention of the visible platform version of the water maze at any of the doses administered. Furthermore, selective inhibition of COX-1 via post-training piroxicam administration had no effect on retention of either task. These findings indicate that COX-2 is a required biochemical component mediating the consolidation of hippocampal-dependent memory.
\end{abstract}

Prostaglandins (PGs) and thromboxanes (TXs), collectively known as prostanoids, are metabolites of arachidonic acid (AA) synthesized and released by most cell types (for review, see Needleman et al. 1986). Although phospholipases initiate prostanoid synthesis by liberating arachidonic acid (5-8-11-14-eicosatetraenoic acid) from membrane fatty acids (for review, see Smith et al. 1991), cyclooxygenase (COX; prostaglandin $\mathrm{H}$ synthetase; prostaglandin-endoperoxide synthase; EC 1.14.99.1) enzymes catalyze the first two committed steps in the biosynthesis of prostanoids. These steps include the oxidation of AA to the hydroperoxy endoperoxide $\mathrm{PGG}_{2}$ and its subsequent reduction to the hydroxy endoperoxide $\mathrm{PGH}_{2}$. $\mathrm{PGH}_{2}$ is then transformed by a variety of enzymes and nonenzymatic mechanisms into the primary prostanoids- $\mathrm{PGE}_{2}, \mathrm{PGD}_{2}, \mathrm{PGF}_{2 \alpha}, \mathrm{PGI}_{2}$ (prostacyclin)-and thromboxane $\mathrm{A}_{2}$ (Vane et al. 1998).

Two COX isoforms, cyclooxygenase-1 (COX-1; DeWitt and Smith 1988) and cyclooxygenase-2 (COX-2; Kujubu et al. 1991; Xie et al. 1991), have thus far been identified. COX-2 is often referred to as the inducible isoform of COX,

${ }^{4}$ Current address: Department of Brain and Cognitive Sciences, Massachusetts Institute of Technology, Cambridge, MA 02139, USA.

${ }^{5}$ Corresponding author.

E-MAIL 1teather@mit.edu; FAX (617) 253-6882.

Article and publication are at http://www.learnmem.org/cgi/doi/ 10.1101/lm.43602. as levels of COX-2 increase in response to several forms of stimulation in various types of tissue (for review, see Vane et al. 1998). In contrast, the constitutive form of COX, COX1 , appears to be involved in housekeeping cellular functions (for reviews, see Smith et al. 1991; Herschmann 1996). Although COX-2 is undetectable in most tissues under basal conditions, marked basal expression has been observed in the dendrites and cell bodies of neurons in the central nervous system (Yamagata et al. 1993; Breder et al. 1995; Kaufman et al. 1996; Teather 1998), indicating a role for COX-2 in cell signaling (Kaufman et al. 1996). Both COX isoforms are present in discrete areas of the mammalian brain (Breder et al. 1992, 1995; Teather 1998), often in speciesand developmental stage-dependent patterns. The functional significance of these enzymes in the mammalian central nervous system is now being actively explored, particularly in pathological situations.

Several lines of evidence indicate a potential role for COX in the physiological mechanisms underlying memory formation. First, nonspecific COX inhibitors impair passive avoidance memory in chicks and prevent the learning-induced increase in PG release, which occurs $2 \mathrm{~h}$ after training (Holscher 1995). Second, COX-2 is expressed in neurons as an immediate early gene (Yamagata et al. 1993) in an NMDA receptor-dependent manner (Yamagata et al. 1993; Lazarewicz and Salinska 1995). This is of particular interest in view of evidence indicating a role for NMDA receptors in

LEARNING \& MEMORY 9:41-47 @ 2002 by Cold Spring Harbor Laboratory Press ISSN1072-0502/02 \$5.00

$$
\begin{aligned}
& \begin{array}{llllllllllllllllllllllllll} 
& E & A & R & N & I & N & G & \bigotimes & & M & E & M & O & R & Y
\end{array} \\
& \text { www.learnmem.org }
\end{aligned}
$$


memory (Mondadori et al. 1989; Morris et al. 1990; Packard and Teather, 1997a,b). A role for COX in information processing has also been previously indicated based on the expression patterns of COX-2, which is predominantly localized in the amygdala, cortex, and hippocampus (Breder et al. 1992, 1995).

The present study investigated the possible significance of the COX enzymes in two distinct forms of mammalian memory. A distinction between the neural substrates that mediate cognitive memory and those that mediate stimulus-response (S-R) habit formation has been previously proposed (Hirsh 1974; Mishkin and Petri 1984; Packard et al. 1989). Evidence from double dissociation experiments involving lesion and intracerebral post-training drug injections indicates that the hippocampal system and dorsal striatum are parts of independent memory systems that may selectively mediate cognitive memory and S-R habit formation, respectively (Packard et al. 1989; Packard and McGaugh 1992, 1996; McDonald and White 1993, 1994; Packard and Teather 1997a, 1998). To assess the significance of COX-1 and COX-2 in these two types of memory, indomethacin (a nonselective COX inhibitor), $\mathrm{N}$-[2-cyclohexyloxy-4-nitrophenyl\&rdqb;-methanesulfonamide, (NS-398; a COX-2 selective inhibitor), and piroxicam (a COX-1 selective inhibitor; Mitchell et al. 1993) were administered after training to rats trained in either a hidden platform or visible platform water maze task, and retention was assessed $24 \mathrm{~h}$ later. In the hippocampus-dependent task (Morris et al. 1982), rats learned to swim to a hidden escape platform located in the same location on each trial, and this task is presumed to involve the acquisition of relational spatial information. In the dorsal striatum-dependent task (Packard and McGaugh 1992; McDonald and White 1994), rats learned to swim to a visibly cued platform that is moved to a new spatial location each trial, and this task may involved the acquisition of a S-R (visible platform-approach) habit.

\section{RESULTS}

\section{Peripheral Administration of $45 \% \mathrm{HBC}$}

A $45 \%$ distilled water-hydroxypropyl- $\beta$-cyclodextrin (HBC) solution was used to aid drug solubilization. HBC is a nontoxic solubilizer with a hydrophilic character that prevents penetration of HBC into the gastrointestinal tract, whereas the complexed drug is readily absorbed (Pitha 1985, 1989). In pilot work, we compared the effects of post-training administration of the water-HBC vehicle and physiological saline, and consistent with our previously published research (Packard and Teather 1997b), we did not observe any behavioral difference between saline-treated rats and the animals administered the $45 \% \mathrm{HBC}$-distilled water vehicle. Only the groups injected with HBC-distilled water vehicle were included for further analyses.

\section{Effect of Post-Training Indomethacin on Retention in the Hidden Platform Task}

A two-way one-repeated-measure ANOVA computed on the escape latencies on the training day revealed no significant group differences $[\mathrm{F}(4,33)=0.478, P=\mathrm{NS}]$. A significant trial effect $[\mathrm{F}(4,7)=67.67, P<0.0001]$ indicated that the rate of task acquisition was similar in all groups. The performance of all groups over the eight hidden platform training trials reached asymptotic performance of 8 to $14 \mathrm{sec}$ (data not shown). These findings indicate that any differences observed in retention test performance among the treatment groups were not caused by differential rates of task acquisition.

The effect of post-training administration of indomethacin on retention in the hidden platform task is shown in Figure 1A. A two-way one-repeated-measure ANOVA computed on the escape latencies revealed a significant group $\times$ trial interaction, $[\mathrm{F}(3,1)=3.1, P<0.05]$, a significant group effect $[\mathrm{F}(3,27)=3.17, P<0.05]$, and a significant trial effect $[\mathrm{F}(1,3)=13.634, P<0.001]$. Scheffe posthoc tests showed that the latencies of rats receiving indomethacin at doses of $5 \mathrm{mg} / \mathrm{kg}(P<0.05)$ and $10 \mathrm{mg} / \mathrm{kg}$ $(P<0.05)$ were significantly higher than those of the salinetreated rats on trial 1 , indicating an impairment in memory.

The retention test escape latencies of rats that received injections of indomethacin $(10 \mathrm{mg} / \mathrm{kg})$ delayed $2 \mathrm{~h}$ posttraining were not significantly different than those of vehicle-treated rats (Fig. 1A). A two-way one-repeated-measure ANOVA computed on the escape latencies revealed a
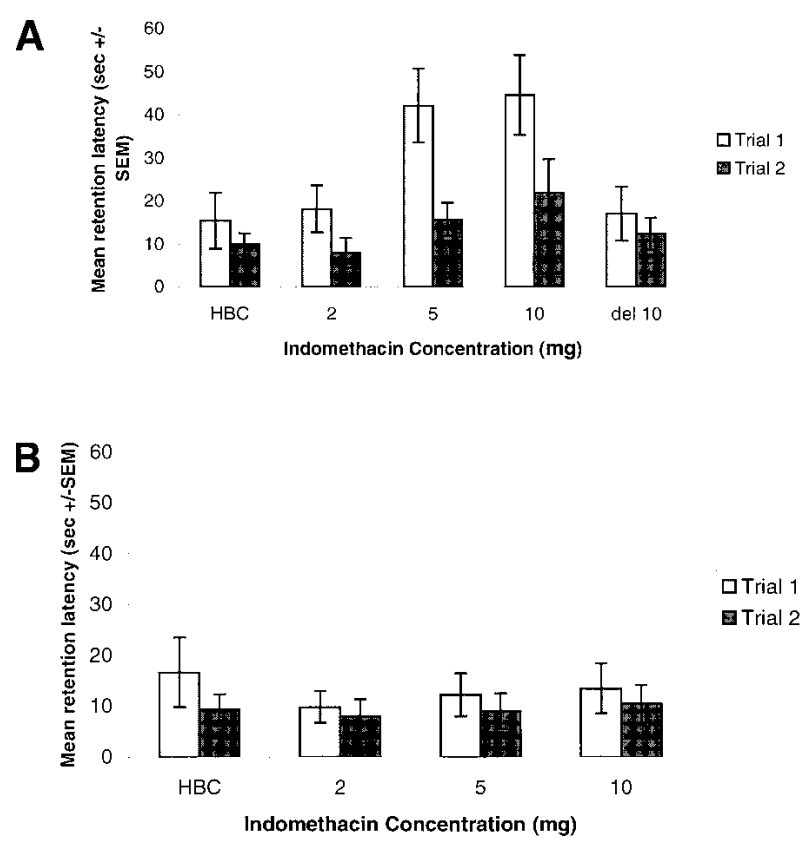

Figure 1 Effect of post-training injections of indomethacin on memory in a hidden $(A)$ and a visible $(B)$ platform water maze task. Retention test escape latencies (seconds \pm SEM) 
nonsignificant group $\times$ trial interaction $[\mathrm{F}(1,1)=3.2$, $P=$ NS $]$ and a nonsignificant group effect $[\mathrm{F}(1,3)=0.258$, $P=\mathrm{NS}]$. A significant trial effect was observed $[\mathrm{F}(1$, $1)=5.071, P<0.05]$, indicating improvement over the two testing trials.

\section{Effect of Post-Training Indomethacin on Retention in the Visible Platform Task}

A two-way one-repeated-measure ANOVA computed on the escape latencies on the training day revealed no significant group differences $[\mathrm{F}(3,27)=2.162, P=\mathrm{NS}]$. A significant trial effect $[\mathrm{F}(3,7)=52.48, P<0.0001]$ indicated that the rate of task acquisition was similar in all groups. The performance of all groups over eight training trials in the visible platform task reached asymptotic performance of 9 to 16 sec (data not shown).

The effect of post-training administration of indomethacin on retention in the visible platform task is shown in Figure 1B. A two-way one-repeated-measure ANOVA computed on the escape latencies revealed a nonsignificant group $\times$ trial interaction $[\mathrm{F}(1,3)=0.165, P=\mathrm{NS}]$, a nonsignificant group effect $[\mathrm{F}(3,28)=0.331, P=\mathrm{NS}]$, and a nonsignificant trial effect $[\mathrm{F}(1,3)=0.163, P<0.001]$, indicating that post-training injections of indomethacin have no influence on retention in the visible platform task.

\section{Effect of Post-Training Piroxicam on Retention in the Hidden Platform Task}

A two-way one-repeated-measure ANOVA computed on the escape latencies on the training day revealed no significant group differences $[\mathrm{F}(3,27)=0.647, P=\mathrm{NS}]$. A significant trial effect $[\mathrm{F}(3,7)=77.86, P<0.01]$ indicated that the rate of task acquisition was similar in all groups. The performance of all groups over eight training trials in the hidden platform task reached asymptotic performance of 9 to 18 sec (data not shown).

The effect of post-training administration of piroxicam on retention in the hidden platform task is shown in Figure 2A. A two-way one-repeated-measure ANOVA computed on the escape latencies revealed a nonsignificant group $\times$ trial interaction $[\mathrm{F}(1,3)=0.426, P=\mathrm{NS}]$ and a nonsignificant group effect $[\mathrm{F}(3,27)=0.131, P=\mathrm{NS}]$, indicating that posttraining injections of the COX-1 inhibitor piroxicam have no influence on retention in the hidden platform task.

\section{Effect of Post-Training Piroxicam on Retention in the Visible Platform Task}

A two-way one-repeated-measure ANOVA computed on the escape latencies on the training day revealed no significant group differences $[\mathrm{F}(3,28)=1.03, P=\mathrm{NS}]$. A significant trial effect $[\mathrm{F}(3,7)=68.51, P<0.001]$ indicated that the rate of task acquisition was similar in all groups. The performance of all groups over eight training trials in the visible
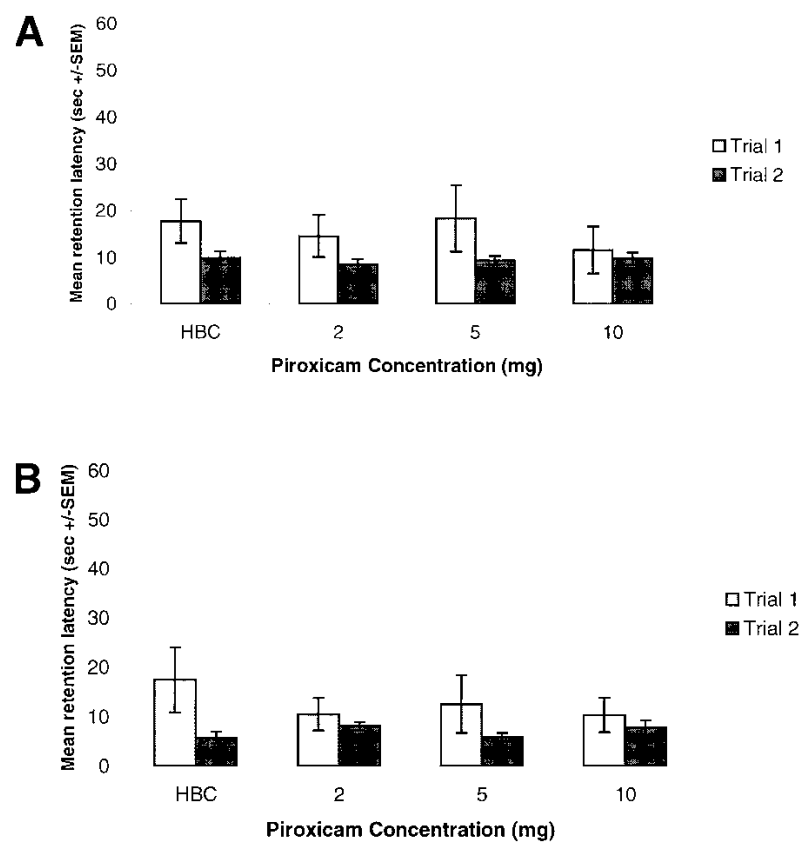

Figure 2 Effect of post-training injections of piroxicam on memory in a hidden $(A)$ and a visible $(B)$ platform water maze task. Retention test escape latencies (seconds \pm SEM)

platform task reached asymptotic performance of 8 to 12 sec (data not shown).

The effect of post-training administration of piroxicam on retention in the visible platform task is shown in Figure 2B. A two-way one-repeated-measure ANOVA computed on the escape latencies revealed a nonsignificant group $\times$ trial interaction $[\mathrm{F}(1,3)=1.4, P=\mathrm{NS}]$ and a nonsignificant group effect $[\mathrm{F}(3,28)=0.311, P=\mathrm{NS}]$, indicating that posttraining injections of piroxicam have no influence on retention in the visible platform task.

\section{Effect of Post-Training NS-398 on Retention in the Hidden Platform Task}

A two-way one-repeated-measure ANOVA computed on the escape latencies on the training day revealed no significant group differences $[\mathrm{F}(4,33)=0.478, P=\mathrm{NS}]$. A significant trial effect $[\mathrm{F}(4,7)=67.67, P<0.0001]$ indicated that the rate of task acquisition was similar in all groups. The performance of all groups over eight training trials in the hidden platform task reached asymptotic performance of 9 to $17 \mathrm{sec}$ (data not shown).

A two-way one-repeated-measure ANOVA computed on the escape latencies revealed a significant group $\times$ trial interaction $[\mathrm{F}(5,31)=8.91, P<0.05]$, a significant group effect $[\mathrm{F}(4,34)=5.41, P<0.002]$, and a significant trial effect $[\mathrm{F}(1,4)=20.172, P<0.0001]$. Tests of simple main effects (group within trial) revealed a significant group effect on retention test trial $1[\mathrm{~F}(4,1)=2.78, P<0.001]$. Scheffe post-hoc tests showed that the latencies of rats re-

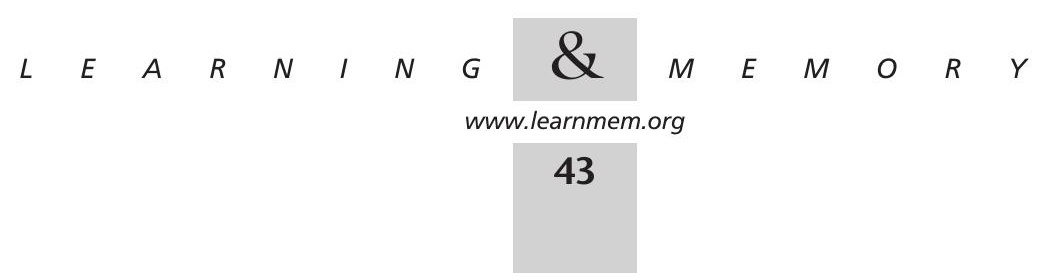


ceiving NS-398 at doses of $2 \mathrm{mg} / \mathrm{kg}(P<0.05)$ and $5 \mathrm{mg} / \mathrm{kg}$ $(P<0.05)$ were significantly higher than those of the salinetreated rats on trial 1 , indicating an impairment in memory (Fig. 3A).

The test escape latencies of rats that received injections of NS-398 $(5 \mathrm{mg} / \mathrm{kg})$ delayed $2 \mathrm{~h}$ post-training were not significantly different than those of vehicle-treated rats (Fig. 3A). A two-way one-repeated-measure ANOVA computed on the escape latencies revealed a nonsignificant group $\times$ trial interaction $[\mathrm{F}(1,1)=0.013, P=\mathrm{NS}]$ and a nonsignificant group effect $[\mathrm{F}(1,3)=0.076, P=\mathrm{NS}]$.

\section{Effect of Post-Training NS-398 on Retention in the Visible Platform Task}

A two-way one-repeated-measure ANOVA computed on the escape latencies on the training day revealed no significant group differences $[\mathrm{F}(3,28)=0.81, P=\mathrm{NS}]$. A significant trial effect $[\mathrm{F}(3,7)=64.9, P<0.001]$ indicated that the rate of task acquisition was similar in all groups. The performance of all groups over eight training trials in the visible platform task reached asymptotic performance of 7 to 13 sec (data not shown).

The effect of post-training administration of NS-398 on retention in the visible platform task is shown in Figure 3B. A two-way one-repeated-measure ANOVA computed on the escape latencies revealed a nonsignificant group $\times$ trial interaction $[\mathrm{F}(1,3)=3.549, P=\mathrm{NS}]$ and a nonsignificant group effect $[\mathrm{F}(3,28)=0.084, P=\mathrm{NS}]$, indicating that post-
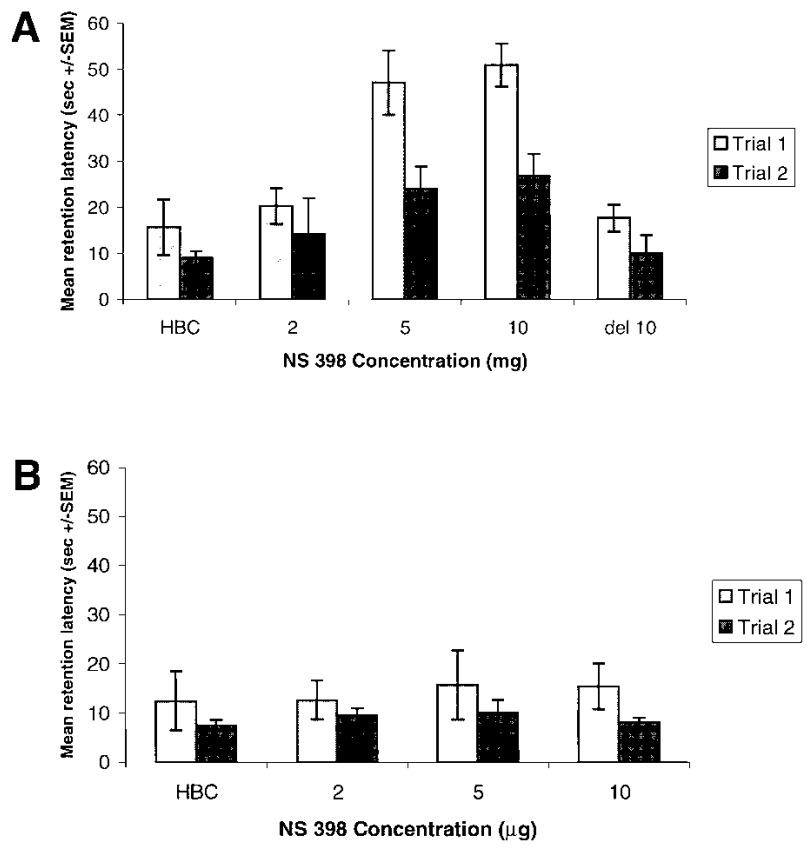

Figure 3 Effect of post-training injections of NS-398 on memory in a hidden $(A)$ and a visible $(B)$ platform water maze task. Retention test escape latencies (seconds \pm SEM) training injections of NS-398 have no influence on retention in the visible platform task.

\section{DISCUSSION}

\section{Effects of Post-Training COX Inhibition on Memory}

Post-training peripheral injection of the nonselective COX inhibitor indomethacin and the COX-2-specific inhibitor NS-398, but not the COX-1-specific inhibitor piroxicam, impaired memory in a hidden platform water maze task. Previous findings indicate that $\mathrm{COX}$ inhibition attenuates learning-induced induction of COX-2 and impairs memory in chicks trained in a passive avoidance task (Holscher 1995). The present findings confirm a role for COX-2 in mammalian memory formation. In cells and purified enzyme studies, indomethacin has been shown to be a nonselective COX inhibitor (Mitchell et al. 1993), piroxicam has been shown to be selective for COX-1 (Laneuville et al. 1884), and NS-398 has been shown to be selective for COX-2 (Futaki et al. 1994; Masferrer et al. 1994). Although the present findings do not rule out a role for COX-1 in memory processes, the differences observed between the behavioral effects of the various COX inhibitors indicate that these isozymes may not play equivalent roles and that COX-2 is the primary isozyme required for memory consolidation. It should be noted that in the present task, the injections of COX-inhibitors occurred $\sim 12$ to $15 \mathrm{~min}$ after the initiation of training (i.e., after the eighth trial in the training session). Therefore, it is conceivable that a role for COX-1 in memory may be present at an earlier time point in the memory formation process. The use of one-trial learning tasks in which the time between initial training and drug administration is shorter (e.g., inhibitory avoidance) may be useful for addressing this possibility.

Injections of indomethacin and NS-398 delayed until 2 $h$ after training did not affect retention, consistent with the hypothesis that the treatments influenced a memory consolidation process (McGaugh 1966, 1973, 1989). Moreover, the time-dependent nature of the treatments indicates that impairing effects of the immediate post-training injections were not caused by a proactive effect of these drugs on nonmnemonic sensory, motivational, attentional, or motor (e.g., swim speed) processes.

In contrast to the impairing effects of COX inhibition in a hidden platform task, post-training administration of indomethacin or NS-398 did not affect memory in a visible platform water maze task. The hidden and visible platform tasks have similar motivational, motoric, and sensory characteristics, indicating that the specific impairment in the hidden platform task is caused by a mnemonic effect of COX-2 inhibition. Acquisition of the hidden platform water maze task is mediated by the hippocampal system (Morris et al. 1982), whereas acquisition of the visible platform task is

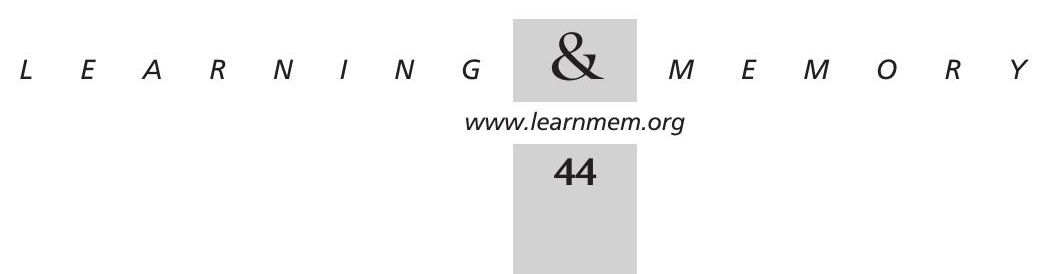


mediated by a separate memory system that includes the dorsal striatum (Packard and McGaugh 1992; McDonald and White 1994; Packard and Teather 1998; Packard 2001). Therefore, the present findings indicate a selective role for COX function in consolidation of hippocampus-dependent cognitive (Hirsh 1974; Mishkin and Petri 1984) memory. Consistent with this suggestion, COX-2 is expressed at relatively high basal levels in the hippocampus (Yamagata et al. 1993; Breder et al. 1995; Teather 1998). Moreover, COX-2 is constitutively expressed at relatively low levels in the striatum (Yamagata et al. 1993; Breder et al. 1995; Teather 1998), which may in part underlie the present finding that COX-2 inhibition did not affect memory in a striatal-dependent task. A dissociation in COX-2 function in the striatum and hippocampus (and cortex) was also suggested by findings that indicate that peripheral NS-398 attenuated postischemic damage in the cortex and hippocampus, yet had no neuroprotective effect in the striatum (Nogawa et al. 1997).

Post-training administration of the COX-1-specific inhibitor piroxicam (three doses) had no effect on retention of either water maze task, indicating that COX-1 does not play a mnemonic role in either hippocampus-dependent cognitive memory or dorsal striatal-dependent S-R habit formation. As COX-1 appears to perform housekeeping cellular functions rather than activity-dependent or plasticity-related functions (Herschman 1996), the observed lack of effect on memory is perhaps not surprising.

\section{Possible Mechanisms of the Impairing Effect of COX-2 Inhibition on Memory}

The present study does not reveal the mechanism(s) by which COX-2 inhibition impairs memory. However, consideration of biochemical and behavioral data from previous studies that examine the roles of various intermediaries in the prostanoid cascade indicates some possibilities. One potential pathway would initially involve the activation of glutamatergic NMDA receptors. An increased level of intracellular calcium after NMDA receptor activation causes a translocation of $\mathrm{CPLA}_{2}$ to the membrane, where it hydrolyzes membrane phospholipids, producing AA (Dumuis et al. 1988; Lazarewicz and Salinska 1995). AA serves as the precursor for prostanoid production, the initial reactions of which are catalyzed by $\mathrm{COX}$. $\mathrm{PGH}_{2}$ is an intermediate formed by the action of COX-2 (or COX-1) and is converted to biologically active prostanoids by specific prostaglandin and thromboxane synthases (for review, see Coleman et al. 1994). Newly formed prostanoids exit the cell via prostaglandin transporters and activate specific $G$ protein-coupled receptors present on the plasma membrane (for review, see Coleman et al. 1994). Prostaglandins are important modulators of adrenergic, noradrenergic (Partington et al. 1980), and glutamatergic (Kimura et al. 1985) neurotransmission.

Neurobehavioral studies support a potential role for various portions of this pathway in memory. For example, extensive evidence indicates a role for NMDA receptor function in memory (Mondadori et al. 1989; Robinson et al. 1989; Packard, and Teather, 1997a,b), and we have previously observed that post-training intrahippocampal infusions of the NMDA receptor antagonist AP5 impairs memory in a hidden platform water maze task (Packard and Teather 1997a). An increase in AA is observed in chick brain slices after training in a passive avoidance task (Holscher et al. 1995), and blockade of $\mathrm{PLA}_{2}$-dependent AA release impairs memory in chicks trained in a passive avoidance task (Holscher and Rose 1994) and in rats trained in a hidden platform water maze task (Holscher et al. 1995). Modulation of adrenergic, noradrenergic, and glutamatergic neurotransmission by prostaglandins could conceivably influence memory processes, as extensive evidence indicates a role for each of these neurotransmitters in memory storage (for review, see McGaugh 1989). In addition to modulating neurotransmission, prostaglandins are involved in the rapid remodeling of actin in the cytoskeleton, and thus can influence the shape of spines and dendrites indicating a potential role for prostaglandins in morphological changes that could conceivably influence synaptic efficiency and information storage.

Finally, in addition to producing AA, cPLA 2 also hydrolyzes membrane phospholipids to produce intracellular platelet activating factor (PAF), a potent bioactive phospholipid (for review, see Bazan et al. 1997). PAF is a putative retrograde messenger in hippocampal long-term potentiation (Clark et al. 1994), and extensive evidence from studies using post-training intracerebral infusions of PAF and PAF receptor antagonists indicates a role for PAF in memory storage processes (Jersusalinsky et al. 1994; Izquierdo et al. 1995; Packard et al. 1996; Teather 1998; Teather et al. 2001). It is of interest to note that PAF has a regulatory effect on the level of COX-2 transcription (Bazan et al. 1994), indicating a possible interaction between intracellular PAF function and prostaglandin pathways in memory. Further research is necessary to reveal the precise mechanism(s) mediating the impairing effects of COX-2 inhibition on memory.

\section{MATERIALS AND METHODS}

\section{Subjects}

Subjects were 203 male Long-Evans rats (330 to $420 \mathrm{~g}$ ) from Charles River Breeding Laboratories (Wilmington, MA). Animals were individually housed in a temperature-controlled 12-h light-dark cycle (lights on 7 a.m. to 7 p.m.). Animals were given ad libitum access to food and water.

\section{Apparatus}

The water maze was a black circular tank $6 \mathrm{ft}(1.83 \mathrm{~cm})$ in diameter and $1.5 \mathrm{ft}(0.55 \mathrm{~cm})$ in height. The tank was filled with water $\left(25^{\circ} \mathrm{C} \pm 2^{\circ} \mathrm{C}\right)$ to a depth of $20 \mathrm{~cm}$ and was located in a well-lit room containing several extramaze cues. Four starting positions (north,

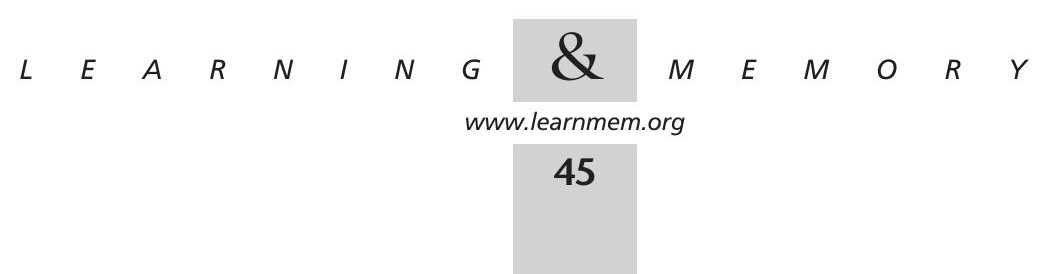


south, east, west) were spaced around the perimeter of the tank, dividing the pool into four equal quadrants. The rectangular Plexiglas escape platform used for the spatial task $(11 \times 14 \times 19 \mathrm{~cm})$ was submerged at a depth of $1 \mathrm{~cm}$. For the visible platform version of the water maze, a white rubber ball $(8 \mathrm{~cm}$ in diameter) was attached to the top of the submerged platform and protruded above the water surface. The platform could be used as a step to mount the ball to escape the water.

\section{Drugs}

Indomethacin, NS-398, and piroxicam (all purchased from Biomol) were dissolved in $45 \% \mathrm{HBC}$ in distilled water (Research Biochemicals International.). HBC is a nontoxic solubilizer with a hydrophilic character that prevents penetration of HBC into the gastrointestinal tract, whereas the complexed drug is readily absorbed (Pitha 1989). Intraperitoneal injections had constant injection volumes of $1 \mathrm{~mL} / \mathrm{kg}$. All solutions were prepared the day of the injections.

\section{Behavioral Procedures}

\section{Hidden Platform Water Maze Task}

The behavioral procedures were identical to those previously described (Packard and McGaugh 1994). Rats received one training session consisting of eight trials (i.e., swims). On each trial, the animal was placed into the tank facing the wall at one of four designated start points (north, south, east, and west) and was allowed to escape onto the hidden platform. The submerged platform was located in the same quadrant on every trial. A different starting point was used on each trial such that each starting point was used twice within the eight trials. If an animal did not escape within $60 \mathrm{sec}$, it was manually guided to the escape platform by the experimenter. After mounting the platform, rats remained on the platform for $20 \mathrm{sec}$. After each trial, animals were removed from the maze and placed in a holding cage for a 30 -sec intertrial interval. The latency to mount the escape platform was recorded and used as a measure of task acquisition. Rats were randomly assigned to treatment groups and were given their respective injections immediately after training (i.e., after the eight trials were completed). Retention was tested $24 \mathrm{~h}$ after the completion of training. The submerged escape platform was located in the same quadrant of the maze as it was during training. Latency to mount the escape platform was recorded for two retention test trials and used as a measure of memory for the training session of the previous day.

Additional groups of rats received delayed post-training injections to control for possible nonmnemonic effects of the immediate injections on retention, such as effects on motivational, sensory, or motor processes (McGaugh 1966, 1973, 1989). Doses used for the delayed injections were selected after examining the effectiveness of the immediate post-training injections.

\section{Visible Platform Water Maze Task}

The behavioral procedures were identical to those previously described (Packard and McGaugh 1994). Rats received one training session consisting of eight trials (i.e., swims). On each trial, the animal was placed into the tank facing the wall at one of four designated start points (north, south, east, and west) and was allowed to escape onto the visibly cued platform. A different starting point was used on each trial such that each starting point was used twice within the eight trials. If an animal did not escape within 60 $\mathrm{sec}$, it was manually guided to the escape platform by the experimenter. After mounting the platform, rats remained on the platform for $20 \mathrm{sec}$. After each trial, animals were removed from the maze and placed in a holding cage for a 30 -sec intertrial interval. The latency to mount the escape platform was recorded and used as a measure of task acquisition.

The visible escape platform was placed in a different quadrant on each trial such that each of the four quadrants contained the escape platform on two of the eight trials. The locations of the start points were arranged so that the distance to the platform (i.e., proximal or distal) and location of the platform relative to the start point (i.e., left or right) were counterbalanced across the eight trials. Rats were randomly assigned to treatment groups and were given their respective injections immediately post-training (i.e., after the eight trials were completed). Retention was tested $24 \mathrm{~h}$ after the completion of training. The visible escape platform was located in a different quadrant of the maze for each test trial. Latency to mount the escape platform was recorded for two retention test trials and used as a measure of memory for the training session of the previous day.

\section{ACKNOWLEDGMENTS}

Research was supported by National Institutes of Health grants NS 23002 (N.G.B.) and 1R2956973 (M.P.).

The publication costs of this article were defrayed in part by payment of page charges. This article must therefore be hereby marked "advertisement" in accordance with 18 USC section 1734 solely to indicate this fact.

\section{REFERENCES}

Bazan, N.G., Fletcher, B.S., Herschman, H.R., and Mukherjee, P.K. 1994. Platelet-activating factor and retinoic acid synergistically activate the inducible prostaglandin synthase gene. Proc. Natl. Acad. Sci. 91: 5252-5256.

Bazan, N.G., Packard, M.G., Teather, L.A., and Allan, G. 1997. Bioactive lipids in excitatory neurotransmission and neuronal plasticity. Neurochem. Int. 30: 225-231.

Breder, C.D., Smith, W.L., Raz, A., Masferrer, J., Seibert, K., Needleman, P., and Saper, C.B. 1992. Distribution and characterization of cyclooxygenase immunoreactivity in the ovine brain. J. Comp. Neurol. 322: 409-438.

Breder, C.D., Dewitt, D., and Kraig, R.P. 1995. Characterization of inducible cyclooxygenase in rat brain. J. Comp. Neurol. 355: 296-315.

Clark, G.D., Happel, L.T., Zorumski, C.F., and Bazan, N.G. 1994. The role of platelet-activating factor in the release of excitotoxic neurotransmitters. J. Lipid Mediators and Cell Signaling 10: 95-97.

Coleman, R.A., Smith, W.L., and Narumiya, S. 1994. International Union of Pharmacology classification of prostanoid receptors: Properties, distribution and structure of the receptors and their subtypes. Pharmacol. Rev. 46: 205-229.

Dewitt, D. and Smith, W.L. 1988. Primary structure of prostaglandin G/H synthase from sheep vesicular gland determined from the complementary DNA sequence. Proc. Natl. Acad. Sci. 85: 1412-1416.

Dumuis, A., Sebben, M., Haynes, L., Pin, J.P., and Bockaert, J. 1988. NMDA receptors activate the arachidonic acid cascade system in striatal neurons. Nature 336: 68-70.

Futaki, N., Takahashi, S., Yokoyama, M., Arai, I., Higuchi, S., and Otomo, S. 1994 . NS-398, a new anti-inflammatory agent, selectively inhibits prostaglandin $\mathrm{G} / \mathrm{H}$ synthase/cyclooxygenase (COX-2) activity in vitro. Prostaglandins 47: 55-59.

Herschman, H.R. 1996. Prostaglandin synthase 2. Biochim. Biophys. Acta 1299: 125-140.

Hirsh, R. 1974. The hippocampus and contextual retrieval of information from memory: A theory. Behav. Biol. 12: 421-442.

Holscher, C. 1995. Inhibitors of cyclooxygenase produce amnesia for a passive avoidance task in the chick. Eur. J. Neurosci. 7: 1360-1365.

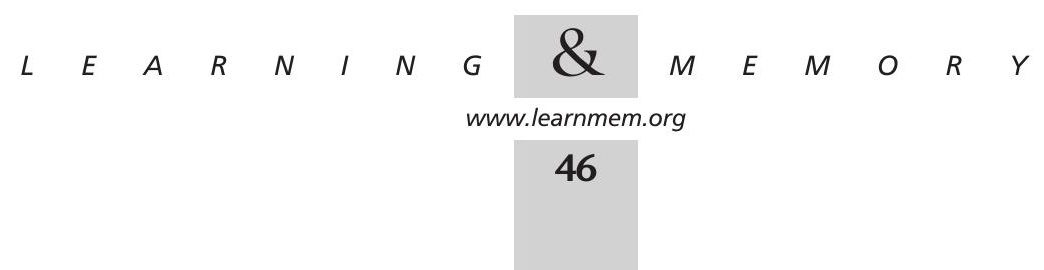


Holscher, C. and Rose, S.P.R. 1994. Inhibitors of phospholipase $\mathrm{A}_{2}$ produce amnesia for a passive avoidance task in the chick. Bebav Neural Biol. 61: 225-232.

Holscher, C., Canevari, L., and Richter-Levin, G. 1995. Inhibitors of PLA and NO synthase cooperate in producing amnesia of a spatial task. Neuroreport 6: 730-732.

Izquierdo, I., Fin, C., Schmitz, P.K., Da Silva, R., Jerusalinsky, D., Quillfeldt, J.A., Ferreiara, M.B.C., Medina, J.H., and Bazan, N.G. 1995. Memory enhancement by intrahippocampal, intraamygdala, or intraentorhinal infusion of platelet-activating factor measured in an inhibitory avoidance task. Proc. Natl. Acad. Sci. 92: 5047-5051.

Jerusalinsky, D., Fin, C., Quillfeldt, J.A., Ferreiara, M.B.C., Schmitz, P.K., Da Silva, R., Walz, R., Bazan, N.G., Medina, J.H., and Izquierdo, I. 1994. Effect of antagonists of platelet-activating factor receptors on memory of inhibitory avoidance in rats. Behav. Neural Biol. 62: 1-3.

Kaufmann, W.E., Worley, P.F., Pegg, J., Bremer, M., and Isakson, P. 1996. COX-2, a synaptically induced enzyme, is expressed by excitatory neurons at postsynaptic sites in rat cerebral cortex. Proc. Natl. Acad. Sci. 93: 2317-2321.

Kimura, H., Okamoto, K., and Sakai, Y. 1985. Modulatory effects of prostaglandin $\mathrm{D}_{2}, \mathrm{E}_{2}$, and $\mathrm{F}_{2 \alpha}$ on the postsynaptic actions of inhibitory and excitatory amino acids in cerebellar Purkinje cell dendrites in vitro. Brain Res. 330: 235-244

Kujubu, D.A., Bradley, S., Fletcher, B.S., Varnum, B.C., Lim, R.W., and Herschman, H.R. 1991. TIS10, a phorbol ester tumor promotor-inducible mRNA from Swiss 3T3 cells, encodes a novel prostaglandin synthase/cyclooxygenase homologue. J. Biol. Chem. 266: 12866-12872.

Laneuville, O., Breuer, D.K., Dewitt, D.L., Hla, T., Funk, C.D., and Smith, W.L. 1994. Differential inhibition of human prostaglandin endoperoxide $H$ synthases-1 and -2 by nonsteroidal anti-inflammatory drugs. J. Pharmacol. Exp. Ther. 271: 927-934.

Lazarewicz, R. and Salinska, E. 1995. $N$-methyl-D-aspartate-evoked release of cyclo-oxygenase products in rabbit hippocampus: An in vivo microdialysis study. J. Neuorsci. Res. 40: 660-666

Masferrer, J.L., Zweifel, B.S., Manning, P.T., Hauser, S.D., Leahy, K.M., Smith, W.G., Isakson, P.C., and Seibert, K. 1994. Selective inhibition of inducible cyclooxygenase 2 in vivo is antiinflammatory and nonulcerogenic. Proc. Natl. Acad. Sci. 91: 3228-3232.

McDonald, R.J. and White, N.M. 1993. A triple dissociation of memory systems: Hippocampus, amygdala, and dorsal striatum. Behav. Neurosci. 107: 3-22.

. 1994. Parallel information processing in the water maze: Evidence for independent memory systems involving the dorsal striatum and hippocampus. Behav. Neural Biol. 61: 260-270.

McGaugh, J.L. 1966. Time-dependent processes in memory storage. Science 153: 1351-1358.

. 1973. Drug facilitation of learning and memory storage. Science 153: 229-240.

1989. Dissociating learning and performance: Drug and hormone enhancement of memory storage. Brain Res. Bull. 23: 339-345.

Mishkin, M. and Petri, H.L. 1984. Memories and habits: Some implications for the analysis of learning and retention. In Neuropsychology of memory (L.R. Squire and N. Butters, eds.), pp. 287-296. Guilford, New York, NY.

Mitchell, J.A., Akarasereenot, P., Thiemermann, C., Flower, R.J., and Vane, J.R. 1993. Selectivity of nonsteroidal antiinflammatory drugs as inhibitors of constitutive and inducible cyclooxygenase. Proc. Natl. Acad. Sci. 90: 11693-11697.

Mondadori, C., Weiskrantz, L., Buerki, H., Petschke, F., and Fagg, G.E. 1989. NMDA receptor antagonists can enhance or impair learning performance in animals. Exp. Brain Res. 75: 449-456.

Morris, R.G.M., Garrud, P., Rawlins, J.N.P., and O'Keefe, J. 1982. Place navigation impaired in rats with hippocampal lesions. Nature 297: 681-683

Morris, R.G.M., Davis, S., and Butcher, S.P. 1990. Hippocampal synaptic plasticity and NMDA receptors: A role in information storage? Philos. Trans. R. Soc. London 329: 187-204.
Needleman, P.J., Turk, B.A., Jakschik, B.A., Morrison, A.R., and Lefkowith, J.B. 1986. Arachidonic acid metabolism. Annu. Rev. Biochem. 55: 69-102

Nogawa, S., Zhang, F., Ross, M.E., and Iadecola, C. 1997. Cyclo-oxygenase-2 gene expression in neurons contributes to ischemic brain damage. J. Neurosci. 17: 2746-2755.

Packard, M.G. 2001. On the neurobiology of multiple memory systems: Tolamn versus Hull, system interactions, and the emotion-memory link. Cogn. Process. 1: 1-22.

Packard, M.G. and McGaugh, J.L. 1992. Double dissociation of fornix and caudate nucleus lesions on acquisition of two water maze tasks: Further evidence for multiple memory systems. Behav. Neurosci. 106: 439-446.

- 1994. Quinpirole and d-amphetamine administration post-training enhances memory on spatial and cued discriminations in a water maze. Psychobiology 22: 54-60.

- 1996. Inactivation of the hippocampus or caudate nucleus with lidocaine differentially affects expression of place and response learning. Neurobiol. Learn. Mem. 65: 65-72.

Packard, M.G. and Teather, L.A. 1997a. Double dissociation of hippocampal and dorsal-striatal memory systems by post-training intracerebral injections of 2-amino-5-phosphonopentanoic acid. Behav. Neurosci. 111: 543-551.

- 1997b. Posttraining injections of MK-801 produce a time-dependent impairment of memory in two water maze tasks. Neurobiol. Learn. Mem. 68: 42-50.

- 1998. Amygdala modulation of multiple memory systems Hippocampus and caudate-putamen. Neurobiol. Learn. Mem. 69: 163-203.

Packard, M.G., Hirsh, R., and White, N.M. 1989. Differential effects of fornix and caudate nucleus lesions on two radial maze tasks: Evidence for multiple memory systems. J. Neurosci. 9: 1465-1472.

Packard, M.G., Teather, L.A., and Bazan, N. G. 1996. Effects of intrastriatal injections of platelet-activating factor and the PAF antagonist BN 52021 on memory. Neurobiol. Learn. Mem. 66: 176-182.

Partington, C.R., Edwards, M.W., and Daly, J.W. 1980. Regulation of cyclic AMP formation in brain tissue by $\alpha$-adrenergic receptors: Requisite intermediacy of prostaglandins of the E series. Proc. Natl. Acad. Sci. 77: 3024-3028.

Pitha, J. 1985. Amorphous water soluble derivatives of cyclodextrins: Non-toxic dissolution enhancing excipients. J. Pharmacol. Sci. 74: 987-990.

1989. Cyclodextrins: Solutions to insolubility. Neurotransmissions 5: $1-4$.

Robinson, G.S., Crooks, G.B., Shinkman, P.G., and Gallagher, M. 1989. Behavioral effects of MK-801 mimic deficits associated with hippocampal damage. Psychobiology 17: 156-164.

Smith, W.L., Marnett, L.J., and. DeWitt, D.L. 1991. Prostaglandin and thromboxane biosynthesis. Pharmacol. Ther. 49: 153-179.

Teather, L.A. 1998. "Neurobiological mechanisms of anatomically and functionally distinct mammalian memory systems." Ph.D thesis, Louisiana State University Medical Center, New Orleans, LA.

Teather, L.A., Packard, M.G., and Bazan, N.G. 1998. Effects of post-training intra-hippocampal injections of platelet-activating factor and PAF antagonists on memory. Neurobiol. Learn. Mem. 70: 349-363.

Vane, J.R., Bakhle, Y.S., and Botting, R.M. 1998. Cyclooxygenases 1 and 2. Annu. Rev. Pharmacol. Toxicol. 38: 97-120.

Xie, W., Chipman, J.G., Robertson, D.K., Erikson, R.L., and Simmons, D.L. 1991. Expression of a mitogen-responsive gene encoding prostaglandin synthase is regulated by mRNA splicing. Proc. Natl. Acad. Sci. 88: $2692-2696$.

Yamagata, K., Andreasson, K.I., Kaufmann, W.E., Barnes, C.A., and Worley, P.F. 1993. Expression of a mitogen-inducible cyclooxygenase in brain neurons: Regulation by synaptic activity and glucocorticoids. Neuron 11: 371-386.

Received August 3, 2001; accepted in revised form December 10, 2001.

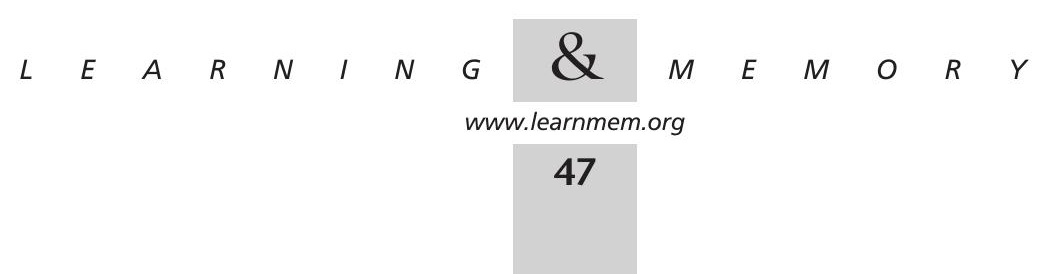




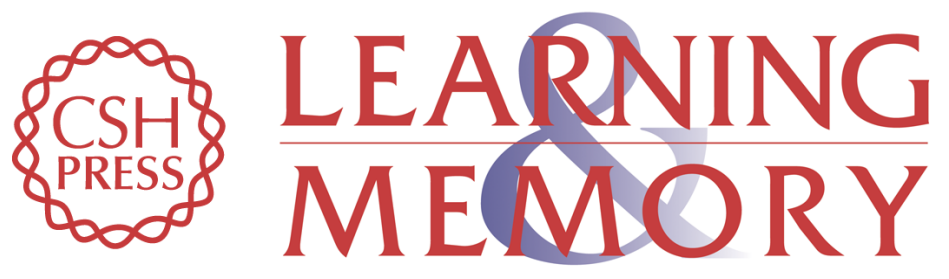

\section{Post-Training Cyclooxygenase-2 (COX-2) Inhibition Impairs Memory Consolidation}

Lisa A. Teather, Mark G. Packard and Nicolas G. Bazan

Learn. Mem. 2002, 9:

Access the most recent version at doi:10.1101/lm.43602

References This article cites 45 articles, 13 of which can be accessed free at: http://learnmem.cshlp.org/content/9/1/41.full.html\#ref-list-1

License

Email Alerting Receive free email alerts when new articles cite this article - sign up in the box at the Service top right corner of the article or click here. 